\title{
Sobre a história do cobalto e da sua relação com a indústria do vidro no Bronze Final
}

\author{
João M. Peixoto Cabral \\ Departamento de Engenharia e Ciências Nucleares, Instituto Superior Técnico, Universidade de Lisboa \\ peixotocabral@sapo.pt
}

\begin{abstract}
On the history of cobalt and of its relationship with the glass industry in Late Bronze Age Cobalt-bearing products began to be used by the mid 2nd millennium BC in the coloration of glass and in the painting of ceramics as soon as glass began to be produced regularly. It is generally accepted that regular glass production must have started in Mesopotamia, but direct evidence for Late Bronze Age (LBA) glass production workshops is only known from Egypt. The raw materials, the production process and the cobalt sources used are summarized. It has been shown by Shortland et al. (2007) that there are consistent compositional differences between glasses found in Mesopotamia and Egypt, which are not related to the colorant but to geological controls. This made it possible, using appropriate techniques of elemental analysis, to determine the provenance of archeological glasses found in various LBA sites and to study the trade of raw glass in that period. Some examples are presented. Glass became relatively rare at the end of LBA, but by the 9th-8th centuries BC the production had already been reestablished. Possible causes of that fall are pointed out.
\end{abstract}

Cobalto começou a ser usado em meados do II milénio a.C. na pintura cerâmica e na coloração do vidro, logo que este começou a ser produzido regularmente. É em geral aceite que a produção regular do vidro teria tido início na Mesopotâmia, mas foi só no Egito que, por enquanto, foram encontrados indícios de oficinas de produção datadas do Bronze Final. Descrevem-se sumariamente as matérias-primas, o processo de produção e as fontes de cobalto utilizadas. Foi demonstrado por Shortland e colaboradores (2007) que existem diferenças de composição consistentes entre os vidros mesopotâmicos e os vidros egípcios, as quais não estão relacionadas com o corante mas com fatores geológicos. Isso tem permitido, recorrendo a técnicas adequadas de análise elementar, determinar a proveniência de vidros arqueológicos achados em vários sítios datados do Bronze Final e estudar o comércio do vidro em bruto nesse período. Apresentam-se alguns exemplos. O vidro tornou-se relativamente raro em finais da Idade do Bronze, mas nos séculos IX-VIII a.C. a sua produção parece ter sido já restabelecida. Apontam-se algumas causas possíveis de tal queda.

O elemento cobalto, de número atómico 27, foi revelado por Georg Brandt (1694-1768) em 1735 numa comunicação à Sociedade Real das Ciências de Upsala sobre os semimetais ${ }^{1}$ [1]. É curioso, porém, que Brandt nunca chegou a precisar quando e como o descobriu. Per Enghag, que se tem dedicado ao estudo da história da química na Suécia, numa primeira averiguação sobre o assunto concluiu que a descoberta teria sido feita em 1730 em ensaios com a cobaltite - mineral composto por cobalto, arsénio e enxofre, de fórmula CoAsS. Contudo, mais tarde, veio a constatar que Torbern Bergman (1735-1784), antigo professor de química da Universidade de Uppsala, num discurso comemorativo proferido em 1769, comunicara que Brandt o descobrira ao analisar a safra — produto utilizado na indústria do vidro, que os saxónios designavam por «Safflor» ou «Saffra» - a fim de perceber a razão pela qual, sempre que ela é adicionada a um vidro liquefeito, o cora de azul. Note-se que, até aí, a causa de tal coloração era atribuída ao bismuto [2,3].

A safra começou a ser fabricada em grande escala na Europa em inícios do século XVI, nomeadamente nos «Erzgebierge» (Montes metalíferos) entre a Saxónia e a

\footnotetext{
1 Brandt definiu semimetais como «corpos que pela forma, massa específica e cor, se assemelham aos metais, diferindo deles por não poderem ser reduzidos a lâmina à martelada». Segundo Brandt, haveria seis semimetais: mercúrio, bismuto, zinco, antimónio, arsénio e cobalto.
}

Boémia, região conhecida pelas suas minas de prata, sendo usada não só como corante na produção de vidro azul-escuro (empregado no fabrico de objetos de adorno, artefactos de luxo, tesselas para mosaico, vidraça para vitral e pigmento azul-de-esmalte ${ }^{2}$ ) mas também como pigmento cerâmico (empregado na pintura de faianças, porcelanas e azulejos). Segundo Beckmann [4], em finais do século XV na região de Schneeberg (Saxónia), juntamente com o minério de prata começou-se a extrair um novo minério - skutterudite, ${ }^{3}$ um arsenieto de cobalto $\left(\mathrm{CoAs}_{3}\right)$ com níquel e ferro em quantidades variáveis - o qual, por inicialmente não lhe reconhecerem qualquer valor, foi sendo posto de parte. Os mineiros temiam-no, em virtude de lhes provocar sérias lesões nos pés, nas mãos, nos pulmões e nos olhos, devido ao arsénio que contém; eles pensavam que os responsáveis por tais moléstias eram os «Kobelts» (ou «Kobolds») - seres fantásticos que, de acordo com a crença da gente daquela região, passeavam pelas minas para os atormentarem. Davam-lhe por isso o nome de «Kobold» [5].

Segundo alguns autores $[4,6]$, quem primeiro se apercebeu da sua utilidade foi Peter Weidenhammer, o qual, por

\footnotetext{
$\overline{2}$ O pigmento azul-de-esmalte, que em inglês, francês e alemão se designa por «smalt», é um vidro potássico com uma pequena percentagem de cobalto, que se vendia moído.

3 A skutterudite era antigamente conhecida por esmaltina.
} 
volta de 1500, decidiu aproveitá-lo como matéria-prima para o fabrico de safra, instalando na região de Schneeberg uma fábrica cujo produto veio a ser em grande parte exportado para Veneza, que desde o século XV era o principal polo da indústria do vidro. Por outro lado, quem tomou a iniciativa de utilizar a safra que aí se produzia para fabricar o pigmento azul-de-esmalte na região de Neudeck (Boémia) foi o vidreiro Christopher Schürer, em 1540.

No entanto, é provável que na Europa a produção de safra remonte a uma época anterior ao século XVI. Com efeito, António de Pisa, mestre em pintura sobre vidro, no seu tratado de arte do vitral redigido por volta de 1395 , menciona um produto de nome chafarone dizendo que vinha da Alemanha e era usado para fazer o «azzurro», ${ }^{4}$ e que se vendia em toda a Europa em pequenos sacos de couro a um preço muito alto [7]. Além disso, conhece-se um texto da «Fondaco dei Tedeschi» (entreposto dos mercadores alemães em Veneza), datado de 1328, no qual se faz referência ao comércio do «caffaranum», um outro nome que os Venezianos davam ao mencionado produto [8]. Ademais, pesquisas efetuadas por Delamare [9] levaram-no a concluir que os filões de cobalto em Freiberg (Saxónia) começaram a ser explorados no século XII, e que nessa época ali se produzia safra que era usada localmente e também exportada.

A safra obtinha-se por ustulação do minério de cobalto num forno de revérbero de chaminé horizontal (Figura 1) onde era transformado em óxido (essencialmente de cobalto), sendo o arsénio libertado na forma de trióxido e escoado para a chaminé na parede da qual se depositava por sublimação. O óxido metálico era então moído e, por fim, misturado com areia quartzosa na proporção de 1:2 a 1:3, em peso [9].

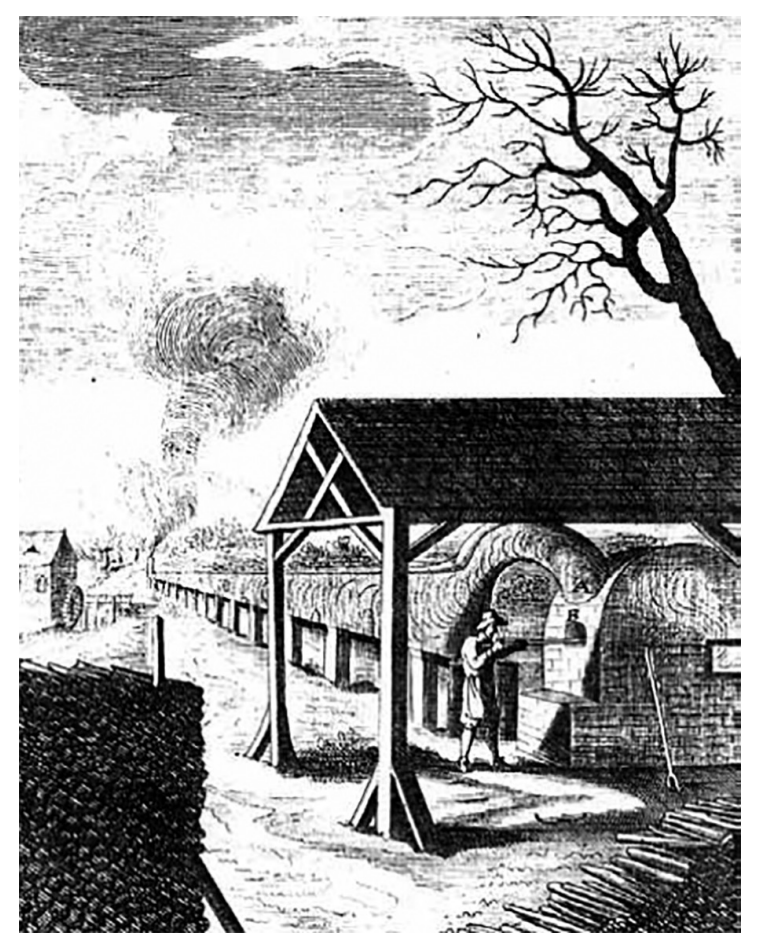

Figura 1 - Oficina e forno para a ustulação do minério de cobalto, na Saxónia [10].

\footnotetext{
4 «'azzurro si se fa di una pietra che se porta de Lamagna che a nome chafarone» [7].
}

É de crer, portanto, que não teria sido difícil para Brandt, efetuando a redução da safra com carbono a temperatura elevada, produzir uma substância metálica — um régulo, como se dizia então. Brandt verificou, quando o régulo era moído e calcinado e depois aquecido juntamente com pedra calcária e um alcali até à fusão da mistura, que se obtinha um vidro idêntico ao azul-de-esmalte. Verificou por outro lado, repetindo a experiência com bismuto em vez do régulo, que o vidro assim originado não era azul. Constatou além disso que, ao contrário do bismuto, o régulo não se amalgamava com o mercúrio. Brandt concluiu, por conseguinte, que a coloração azul que o vidro adquire quando se lhe adiciona safra não é devida ao bismuto mas a um novo elemento ao qual deu o nome de Kobolt, ${ }^{5}$ o mesmo que os mineiros da Saxónia tinham posto ao temível minério. Deve sublinhar-se, contudo, que houve quem levantasse dúvidas quanto à pureza do régulo e, consequentemente, quanto à real existência do pretenso elemento.

Em 1742, Brandt [11] comunicou a descoberta de um novo mineral de cobalto - a lineíte, um sulfureto simples de fórmula $\mathrm{Co}_{3} \mathrm{~S}_{4}$ - , e em 1748, partindo deste mineral, produziu cobalto no estado metálico e mostrou que ele é ferromagnético e forma ligas com outros metais, designadamente, ferro, estanho, cobre, ouro e antimónio [12]. Não obstante, foi só em 1780 que a existência do elemento cobalto veio a ser confirmada por Torbern Bergman.

O uso de substâncias cobaltíferas na coloração do vidro e na pintura cerâmica é, porém, muito anterior ao início do fabrico da safra na Europa, remontando à época em que o vidro começou ser produzido regularmente na Mesopotâmia e no Egito, ou seja, a meados do II milénio a.C.. A história do cobalto está, pois, estreitamente relacionada com a história do vidro.

O presente artigo tem como objetivo traçar um esboço da história conjunta do cobalto e do vidro relativa à segunda metade do referido milénio. A exposição será feita de acordo com a seguinte ordem: 1) as primeiras aplicações de produtos cobaltíferos; 2) a produção do vidro; 3) recursos de minerais cobaltíferos; 4) diferenças de composição entre vidros egípcios e mesopotâmicos; 5) o comércio do vidro; 6) a crise civilizacional em finais da Idade do Bronze e consequências.

\section{As primeiras aplicações de produtos cobaltíferos}

O uso de produtos cobaltíferos começou a fazer-se no Egito e na Mesopotâmia, no século XV a.C., seja para colorir de azul o vidro seja para pintar cerâmicas.

\footnotetext{
A cor azul dos vidros coloridos com cobalto é devida a transições eletrónicas d-d. Nestes vidros, os iões $\mathrm{Co}^{2+}$ (de configuração eletrónica $[\mathrm{Ar}] 3 \mathrm{~d}^{7}$ ), encontram-se rodeados sobretudo por quatro iões de oxigénio $\mathrm{O}^{2-}$ e a presença do campo elétrico (tetraédrico) por eles criado provoca no cobalto o desdobramento das suas cinco orbitais d em dois grupos: o das orbitais de alta energia $\boldsymbol{t}_{2 g}$ (dxy, dxz, dyz) e o das orbitais de baixa energia $\boldsymbol{e}_{g}\left(\mathrm{dz}^{2}, \mathrm{dx}^{2}-\mathrm{dy}^{2}\right)$, sendo a diferença de energia $\Delta_{t}$ da ordem de grandeza da energia da radiação visível. A cor azul deve-se à promoção dum eletrão de uma orbital $\boldsymbol{e}_{g}$ para uma orbital $\boldsymbol{t}_{2 q}$ em resultado da absorção de luz de energia $\Delta_{t}$. Esta energia está representada no espetro de absorção por uma banda com um máximo a cerca de $530 \mathrm{~nm}$.
} 
A cerâmica egípcia do período dinástico (3000-332 a.C.), ${ }^{6}$ em geral, não apresenta decoração. No entanto, no período correspondente às dinastias XVIII, XIX e XX, designado por Império Novo (c. 1560-1070 a.C.), sobretudo entre 1400 e 1200 a.C., teriam sido produzidas quantidades significativas de cerâmica decorada, na qual a decoração é predominantemente azul com desenhos a vermelho e/ou castanho avermelhado [13]. Daí que a essa cerâmica se desse o nome de «pintada a azul». Na Figura 2 mostra-se um exemplo, relativo ao tempo do faraó Amen-hotep III (c. 1390-1352 a.C.) da XVIII dinastia. Em 1974, Riederer [14] verificou que o azul da decoração é devido à presença do cobalto e não do cobre. Por seu turno, em 1981, Noll [15] demonstrou que o cobalto se apresenta na forma de uma espinela de Co-Al, e sugeriu que ela teria sido produzida a partir dos alúmenes cobaltíferos do Deserto Ocidental do Egito.

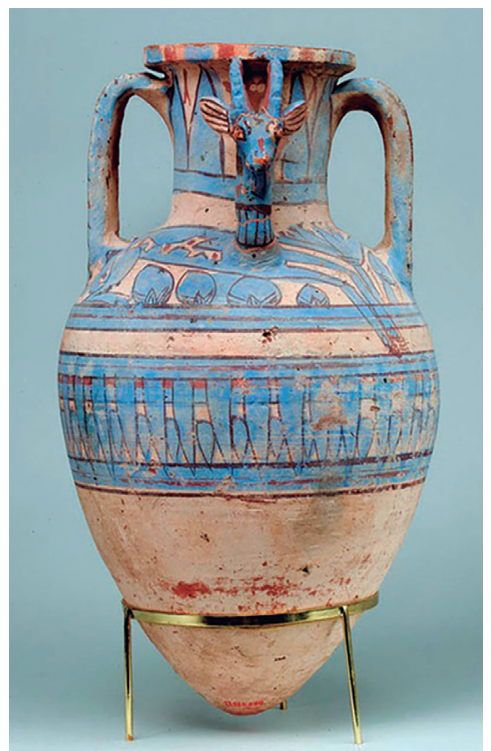

Figura 2 - Ânfora “pintada a azul”, achada no palácio residencial de Amen-hotep III (c. 1390-1352 a.C.), em Malkata. ${ }^{7}$ The Metropolitan Museum of Art, Nova Iorque.

Ao contrário da cerâmica "pintada a azul”, o vidro e a faiança ${ }^{8}$ azuis achados no Egito são comuns desde o III milénio a.C. Verifica-se, porém, que tanto nos vidros como nas faianças anteriores ao reinado de Tutmés III (14791427 a.C.) o azul não é devido ao cobalto mas ao cobre. A razão pela qual não foi encontrada cerâmica decorada a

\footnotetext{
${ }^{6}$ Foi Maneton, historiador egípcio do início do século III a.C., quem estabeleceu a divisão dos soberanos do Egito em trinta dinastias, a qual ainda é hoje seguida. A primeira dinastia inicia-se em c. 3000 a.C. e a trigésima termina em 332 a.C. com o final do domínio persa sobre o Egito.

7 Malkata é um sítio arqueológico situado na margem ocidental do rio Nilo, no lado oposto a Luxor (antiga cidade de Tebas), o qual deve a sua importância aos vestígios do palácio de Amen-hotep III.

8 A faiança egípcia é um material cerâmico produzido a partir duma pasta constituída por sílica, soda, cal e pequenas quantidades doutras substâncias, como os óxidos de cobre e de cobalto. Essa pasta era usada para moldar diversos artefactos - contas, escaravelhos, selos, amuletos, figurinhas, estatuetas, etc. — os quais eram depois aquecidos num forno. Devido ao aquecimento, tais artefactos adquiriam não só consistência mas também um vidrado superficial brilhante, de cor em geral azul ou azul esverdeado, que os egípcios associavam às superfícies luzidias de pedras preciosas [17].
}

azul anterior a esse reinado poderá estar relacionada com a dificuldade em pintar peças de cerâmica usando um pigmento de cobre por forma a que a decoração se conserve durante muito tempo.

A coloração do vidro fazia-se vulgarmente nas oficinas de produção (designadas na gíria arqueológica por primárias), sendo depois vendido a oficinas artesanais (chamadas secundárias) localizadas muitas vezes bastante longe das oficinas de produção, onde era então trabalhado por artesãos e convertido em artefactos [16].

Assim, tudo leva crer que foi a partir do reinado de Tutmés III (século XV a.C.) que se teria começado a usar produtos cobaltíferos, quer para pintar artefactos de cerâmica quer para colorir vidros e vidrados, práticas essas que se tornaram comuns nos reinados do seu filho Amen-hotep II (1427-1400 a.C.) e do seu neto Tutmés IV (1400-1390 a.C.), atingindo o auge no período compreendido entre este último reinado e o ano de 1200 a.C. A título de exemplo, apresenta-se na Figura 3 um vaso de vidro colorido com cobalto, da época de Amen-hotep III, e na Figura 4 uma faiança da mesma época cuja cor se deve também ao cobalto.

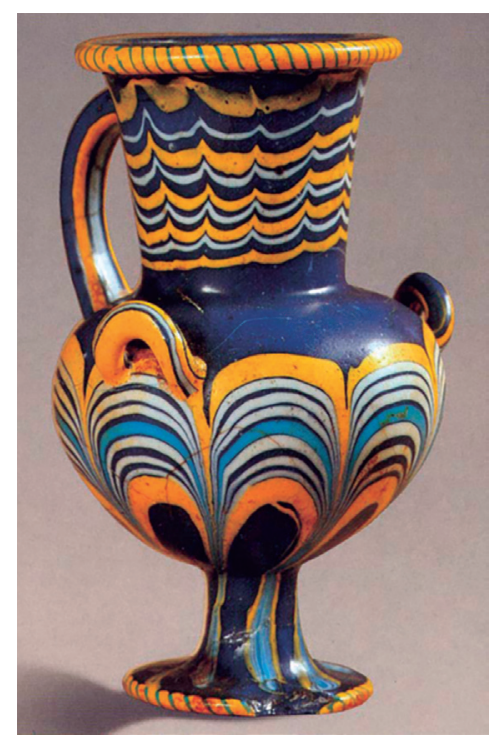

Figura 3 - Vaso em vidro azul-escuro, com decorações em vidro branco, amarelo e azul-claro (1390-1352 a.C.). 9,5 cm. Museu Egípcio, Cairo.

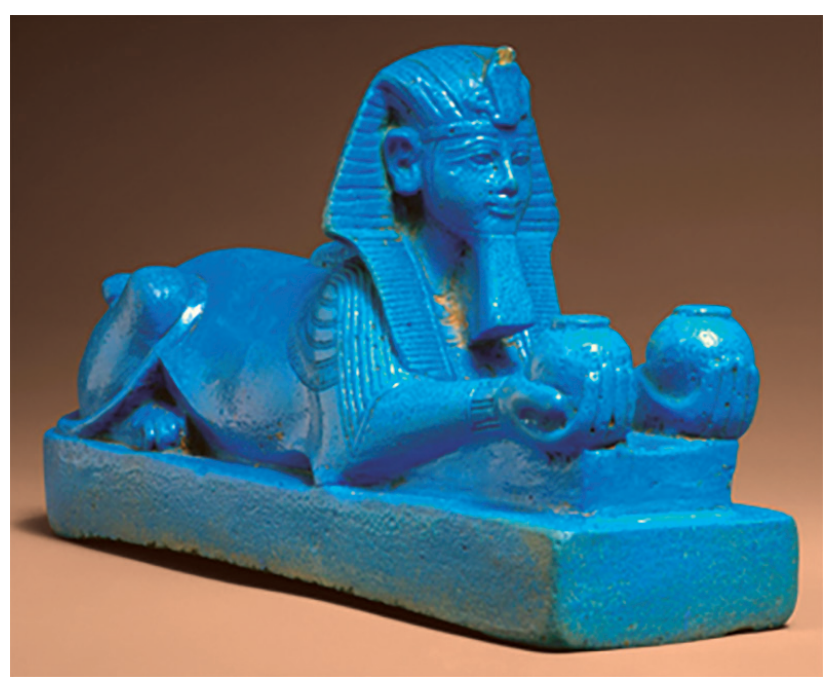

Figura 4 - Esfinge de Amen-hotep III, em faiança (1390-1352 a.C.). 25,1 x 13,3 x 13,3 cm. The Metropolitan Museum of Art, Nova Iorque. 
É de salientar, todavia, que o aparecimento de artefactos arqueológicos em vidro e em cerâmica, datados dos séculos XV-XII a.C., nos quais se verificou a presença do cobalto, não se tem limitado apenas ao Egito e à Mesopotâmia. Tem ocorrido também em muitas regiões do Próximo Oriente e da bacia do Mediterrâneo - Levante, Chipre, Creta, Grécia continental e Itália setentrional -, assim como em regiões da Europa Central e Setentrional.

\section{A produção do vidro}

É geralmente aceite, com base em estudos arqueológicos e filológicos, que o vidro teria começado a ser produzido de modo regular na Mesopotâmia por volta de 1550 a.C., e só mais tarde no Egito. Nas escavações até agora realizadas na Mesopotâmia verificou-se, porém, que em nenhum dos sítios onde foram achados fragmentos de vidro datados de finais da Idade do Bronze — os principais dos quais são Nippur, ${ }^{9}$ Nuzi $^{10}$ e Tell Brak ${ }^{11}$ (Figura 5) — se encontraram vestígios arqueológicos de oficinas de produção de vidro (primárias), mas apenas de oficinas de manufatura de artefactos (secundárias).

Pelo contrário, nas escavações efetuadas no Egito, além de indícios da existência de oficinas de manufatura de artefactos, têm sido descobertos nos últimos tempos vestígios claros de oficinas de produção de vidro remontando à referida época, particularmente nos sítios de Pi-Ramsés ${ }^{12}$ [18], Amarna ${ }^{13}$ [19] e Licht ${ }^{14}$ (Figura 5) [20].

Em Pi-Ramsés, chegou-se mesmo a recolher uma enorme quantidade de fragmentos de cerâmica, os quais, uma vez selecionados e unidos adequadamente, permitiram restaurar cerca de três centenas de recipientes usados nas operações de produção do vidro. Destes recipientes, mais de $90 \%$ são cadinhos aproximadamente cilíndricos,

\footnotetext{
${ }^{9}$ Nippur foi uma das mais antigas cidades da Mesopotâmia, com uma história que abrange o período desde o VI milénio a.C. até ao século IX d.C. O sítio, conhecido atualmente pelo nome de Nuffar, situa-se a $c .169 \mathrm{~km}$ a sudeste de Bagdade. As primeiras grandes escavações arqueológicas que aí foram feitas datam de 1888-1900.

10 Nuzi foi uma antiga cidade da Mesopotâmia cujo sítio, atualmente conhecido pelo nome de Yorghan Tepe, se situa a sudoeste de Kirkouk, próximo do Tigre, no Iraque.
}

11 Tell Brak é um sítio arqueológico com vestígios de ocupação desde o VII milénio a.C. até ao I milénio d.C., onde se localizava a antiga cidade de Nagar, o qual deve o nome à circunstância de se situar próximo da atual povoação de Tell Brak, no nordeste da Síria.

12 Pi-Ramsés, que se situa no lugar da atual Qantir, na parte oriental do Delta do Nilo, foi uma cidade fundada por Ramsés II (1279-1213), faraó da XIX dinastia, e capital do Egito durante esta dinastia e a seguinte.

13 Amarna, ou Tell el Amarna, é o nome que se dá atualmente ao sítio onde se localizava a efémera capital do Antigo Egito - Akhetaton —, fundada por Amen-hotep IV (1352-1336 a.C.), também chamado Akhenaton, a qual só foi habitada durante c. 25 anos. Situa-se na margem direita do Nilo, a c. $300 \mathrm{~km}$ do Cairo, sendo lá que foi achado o busto da bela Nefertiti, mulher de Akhenaton, atualmente em exposição no Neues Museum de Berlim.

14 O sítio de Licht, situado a cerca de $65 \mathrm{~km}$ a sul do Cairo, deve a sua celebridade à primeira necrópole real da XII dinastia, fundada por Amenemhat I (1985-1956 a.C.). Porém, os achados relativos à produção do vidro datam das XIX e XX dinastias, provavelmente do período compreendido entre 1295 e 1070 a.C. revestidos na parte interior por uma fina camada de cal e apresentando por vezes substâncias vítreas aderentes; os restantes são quase todos vasos de forma ovoide, com um revestimento interno semelhante ao dos cadinhos.

Análises efetuadas às referidas substâncias vítreas e à cerâmica de que são feitos os vasos e cadinhos, incluindo a determinação do seu grau de vitrificação, permitiram a Rehren e Pusch [18,21,22] identificar as matérias-primas usadas na produção do vidro - seixos de quartzo-branco e cinzas de plantas ${ }^{15}$ — e recriar o processo de fabrico, o qual consistiria no seguinte: numa primeira fase, os seixos eram moídos, o pó obtido misturado com cinzas e a mistura aquecida num vaso ovoide, a temperatura relativamente baixa (estimada em $c .900^{\circ} \mathrm{C}$ ), donde resultava a formação de um vidro semiacabado, ainda com bastantes grãos de quartzo e restos de cristais ricos em cal: numa segunda fase, o vidro era moído, o pó obtido lavado e transferido para um cadinho cilíndrico (provavelmente com mais cinzas), a mistura aquecida a temperatura superior à estabelecida na primeira fase (talvez c. $1050^{\circ} \mathrm{C}$ ) até o vidro se liquefazer completamente e, por último, o corante adicionado. O cadinho era depois deixado a arrefecer, o que dava origem à formação de um lingote de vidro aproximadamente cilíndrico. Nas escavações efetuadas em Pi-Ramsés chegou-se mesmo a encontrar um lingote de vidro vermelho ${ }^{16}$ inteiro, cujas dimensões (diâmetro médio de $c .12 \mathrm{~cm}$, altura de $c .10 \mathrm{~cm}$ ) se ajustam bem às do interior dos cadinhos cilíndricos.

Em Amarna, os primeiros indícios do fabrico de vidro (restos de frita em vasos cerâmicos) foram descobertos pelo egiptólogo William Petrie em finais do século XIX, o que o levou a sugerir que nesta antiga e efémera cidade teria havido uma oficina de produção de vidro [24]. Tal sugestão começou a ganhar credibilidade em meados do século XX, com a descoberta de novos indícios, sobretudo de cadinhos cilíndricos utilizados na produção de lingotes de vidro. Mas foi só há pouco tempo que, em Amarna, se encontrou a primeira evidência arqueológica direta do fabrico de vidro, designadamente, um conjunto de 35 fragmentos de vidro semiacabado [25]. Segundo Jackson e Nicholson, este vidro semiacabado não se distingue do vidro semiacabado encontrado em Pi-Ramsés, sendo portanto coerente com o método de fabrico em duas fases acima referido; e, tal como o de Pi-Ramsés, não contém corante intencionalmente adicionado, embora se apresente por vezes com uma certa quantidade de antimónio usado como opacificante.

É de notar que, à semelhança dos cadinhos achados em Pi-Ramsés, os cadinhos cilíndricos descobertos em Amarna contêm na sua maioria vestígios de vidro colorido. Contudo, enquanto nos de Pi-Ramsés o vidro é predominantemente vermelho, nos de Amarna é azul, sobretudo azul-cobalto.

\footnotetext{
15 As cinzas usadas como fundente no fabrico do vidro durante o Bronze Final eram obtidas a partir de plantas halófitas dos géneros Salicornia e Salsola, que crescem nalgumas regiões desérticas, semidesérticas e litorais acumulando sódio e, em menor grau, potássio. Elas são por isso ricas em sódio [23].

16 O vidro vermelho, comum em Pi-Ramsés, obtinha-se usando como corante o cobre e operando em meio redutor. Era muito mais difícil de produzir do que o vidro azul-cobalto, exigindo muito mais perícia e saber-fazer.
} 


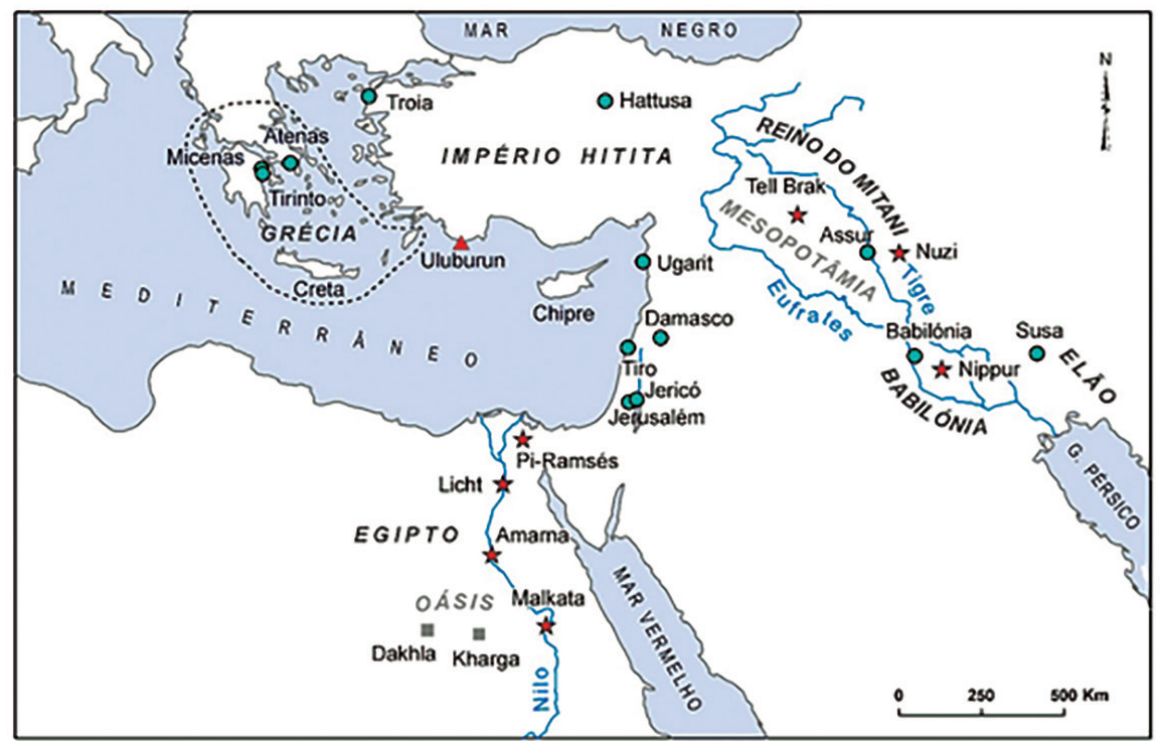

Figura 5 - Mapa indicando os principais sítios onde se encontraram vidros datados de finais da Idade do Bronze, designadamente, Pi-Ramsés, Amarna, Malkata e Licht (no Egito) e Nippur, Nuzi e Tell Brak (na Mesopotâmia).

Em Licht, descobriram-se recentemente alguns testemunhos arqueológicos evidentes do fabrico de vidro, tais como pedaços de vidro semiacabado e fragmentos de cadinhos com vidro aderente (principalmente azul mas também de outras cores). Foram ainda achados lingotes de vidro [20].

Há que sublinhar, porém, que o principal achado de lingotes de vidro do Bronze Final foi, até agora, um conjunto de 175 lingotes de vidro-azul (pesando na sua totalidade $c$. $400 \mathrm{~kg}$ ), os quais estavam num barco naufragado ao largo da costa da Turquia, em Uluburun, barco esse que, de acordo com a data dendrocronológica determinada para os troncos de árvore que juntamente levava, deve ter-se afundado pouco tempo depois de 1300 a.C. [26]. Embora muitos destes lingotes estivessem bastante corroídos, havia alguns em estado razoável de conservação, todos praticamente cilíndricos, sendo a maioria de vidro azul-escuro e os restantes de vidro azul-turquesa (Figura 6). As análises efetuadas a estes vidros mostraram que nos azuis-escuros a cor é devida ao cobalto e nos azuis-turquesa ao cobre. Como se pode ver na Figura 7, os lingotes coloridos com cobalto são, em média, um pouco maiores que os coloridos com cobre (particularmente mais altos) e menores que o lingote de Pi-Ramsés, indicando que proviriam de oficinas de produção distintas [28], o que veio a confirmar-se posteriormente como se mostrará mais à frente.

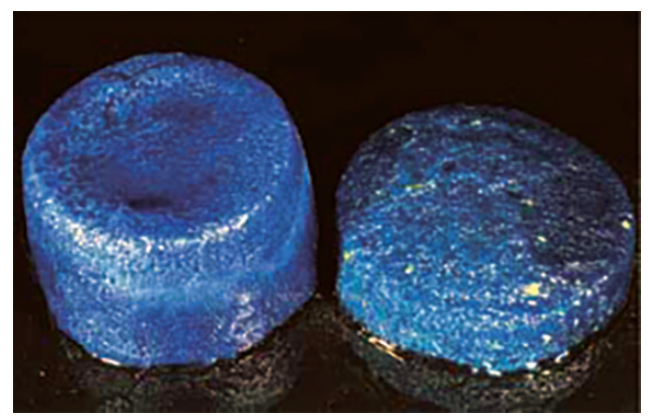

Figura 6 - Lingotes de vidro encontrados num barco naufragado em $c$. 1300 a.C. ao largo da costa da Turquia, em Uluburun: colorido com cobalto (à esquerda); colorido com cobre (à direita) [27].

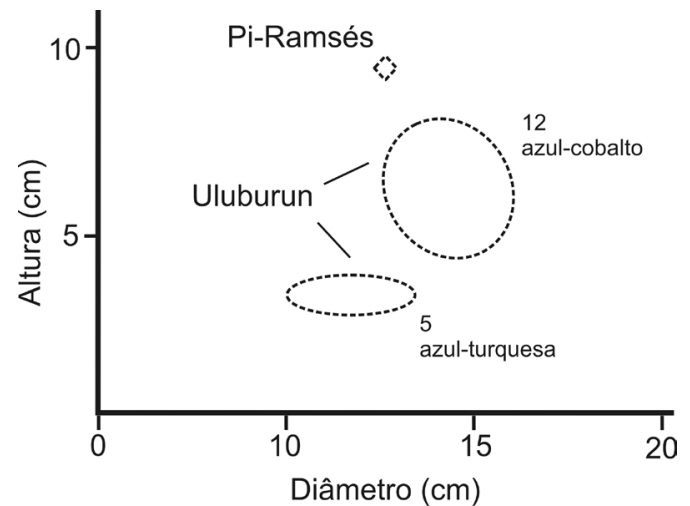

Figura 7 - Comparação das dimensões de 17 lingotes de vidro achados no barco naufragado em Uluburun (12 azul-cobalto e 5 azul-turquesa) e do lingote de Pi-Ramsés (vermelho) [28].

\section{Recursos de minerais cobaltíferos}

Durante o Império Novo, os minérios de cobalto usados na coloração de vidros e vidrados foram, com toda a probabilidade, os alúmenes ${ }^{17}$ cobaltíferos do oásis de Dakhla, situado no Deserto Ocidental do Egito. Na verdade, efetuando a análise elementar de diversos vidros egípcios, uns coloridos com cobalto e outros coloridos com cobre, Kaczmarczyk [29] verificou: 1) que as concentrações de cobalto, alumínio, manganês, níquel e zinco determinadas nos vidros coloridos com cobalto são mais elevadas do que as determinadas nos vidros coloridos com cobre; 2) que tais elementos se encontram fortemente correlacionados uns com os outros. Por outro lado, analisando algumas amostras de alúmenes cobaltíferos colhidas numa formação do oásis de Dakhla, Kaczmarczyk constatou que eles são sulfatos de alumínio e magnésio contendo vestígios de ferro, manganês, cobalto, níquel e zinco, em proporções aproximadamente iguais às determinadas nos vidros egípcios coloridos com cobalto.

17 Stricto sensu, alúmen é o sulfato duplo de alumínio e potássio hidratado, $\mathrm{KAl}\left(\mathrm{SO}_{4}\right)_{2} \cdot 12 \mathrm{H}_{2} \mathrm{O}$, a que se dá vulgarmente o nome de pedra-ume. Lato sensu, alúmenes são sulfatos duplos hidratados de alumínio e um outro elemento, que pode ser alcalino, alcalinoterroso ou de transição. 
Mais tarde, Shortland e Tite [30] procuraram avaliar a extensão da referida formação e, por outro lado, prospetar outros alúmenes cobaltíferos no oásis de Kharga, situado também no Deserto Ocidental do Egito, efetuando a análise elementar de uma série de amostras colhidas em diversos lugares de ambos os oásis. Os resultados obtidos mostraram que nalguns lugares do oásis de Kharga se encontram também depósitos de alúmenes cobaltíferos, os quais, no que diz respeito aos elementos vestigiais manganês, níquel e zinco, possuem características semelhantes às dos depósitos do oásis de Dakhla. Todavia, os autores constataram que, tanto neste oásis como no de Kharga, os alúmenes se acham muito dispersos e com teores de cobalto relativamente baixos e muito variáveis.

Por seu turno, num estudo sobre o pigmento azul-escuro utilizado pelos egípcios para decorar a cerâmica «pintada a azul», Shortland e Tite [30] confirmaram uma antiga sugestão de Noll [15] de que tal pigmento teria sido produzido a partir dos alúmenes cobaltíferos do Deserto Ocidental do Egito. Com efeito, analisando o pigmento azul presente nalguns cacos desta cerâmica, colhidos em Malkata e Amarna, aqueles investigadores mostraram que ele se caracteriza por teores elevados de alumínio, magnésio, manganês, ferro, níquel e zinco, em proporções semelhantes às que se verificam nos referidos alúmenes. Notaram, contudo, que os alúmenes usados para produzir este pigmento teriam uma composição um pouco diferente da dos usados para colorir os vidros, seja por terem sido extraídos de depósitos diferentes, seja por terem sido submetidos a diferentes tratamentos conforme o fim a que se destinavam.

Na Mesopotâmia, a produção de vidro colorido com cobalto, a julgar pela raridade dos achados, deve ter sido relativamente escassa, sendo o vidro azul quase todo colorido com cobre. Parece que o minério cobaltífero aqui utilizado não proviria dos oásis do Deserto Ocidental do Egito. Na verdade, Walton e colaboradores [31] verificaram, efetuando a análise elementar do vidro azul-cobalto de que são feitas as cabeças de certos machados cerimoniais dos séculos XIV-XIII a.C., achados em Nippur, que tais vidros apresentam uma composição bastante diferente da dos vidros coloridos com cobalto produzidos no Egito, particularmente no que diz respeito aos elementos característicos dos alúmenes dos referidos oásis. Não lhes foi possível, porém, identificar a fonte de cobalto.

\section{Diferenças de composição entre vidros egípcios e mesopotâmicos}

Como vimos atrás, o fabrico do vidro no Egito durante o Bronze Final foi em geral realizado usando como fundente cinzas de plantas, ricas em sódio. Consequentemente, os vidros produzidos no Egito nessa época são na sua maioria vidros calco-sódicos (10-20\% $\left.\mathrm{Na}_{2} \mathrm{O}\right)$, com percentagens de magnésio e potássio relativamente elevadas (2-8\%). Verificou-se, por outro lado, que os vidros arqueológicos achados na Mesopotâmia, em contextos da mesma época, são igualmente calco-sódicos.

Desde há várias décadas que se tem procurado averiguar se há diferenças de composição significativas entre os vidros egípcios e mesopotâmicos mediante a análise elementar. Todavia, devido, por um lado, ao facto de tais vidros serem do mesmo tipo (de composições semelhantes no respeitante aos elementos maiores e menores) e, por outro lado, à circunstância de os métodos de análise então disponíveis não possuírem sensibilidade, precisão e exatidão suficientes para tal efeito, todas as tentativas realizadas até ao princípio deste século foram infrutíferas, mesmo incluindo na análise alguns elementos vestigiais.

Foi só após o aparecimento de métodos mais sensíveis, precisos e rigorosos, e praticamente não-destrutivos, como o método de LA-ICPMS, ${ }^{18}$ que Shortland e colaboradores [32], analisando por este método 32 elementos vestigiais em 54 amostras de vidros, incolores e azuis (uns coloridos com cobalto, outros com cobre, e outros ainda com cobre e cobalto), provenientes de quatro sítios arqueológicos dois no Egito (Malkata e Amarna) e dois na Mesopotâmia (Nuzi e Tell Brak) —, conseguiram diferençar os vidros egípcios dos vidros mesopotâmicos. Provaram, além disso, que os elementos vestigiais discriminantes (nomeadamente titânio, crómio, zircónio e lantânio) não estão relacionados com a coloração dos vidros mas com as matérias-primas usadas no seu fabrico (e, talvez, com o processo de fabrico), matérias-primas essas cuja composição é variável de região para região.

O desenvolvimento de métodos poderosos de análise elementar como o de LA-ICPMS veio, pois, abrir caminho para a realização de estudos do comércio do vidro no Bronze Final, através da determinação da sua proveniência. Destes estudos apresentam-se a seguir alguns exemplos.

\section{O comércio do vidro}

Conhecem-se documentos escritos, nomeadamente as Cartas de Amarna ${ }^{19}$ EA 148, EA 323 e EA 331 [33], que mostram que o faraó Akhenaton encomendou vidro a reis e governadores de países do Próximo Oriente, vassalos do Egito, e que estes acusaram a receção das encomendas informando-o sobre as quantidades fornecidas.

A importação egípcia de vidro, no tempo de Akhenaton, foi confirmada por Varberg e colaboradores [34] mediante a análise elementar de duas varetas de vidro verde encontradas por Petrie [24] nas suas escavações em Amarna, cujos resultados mostraram que este vidro tem uma composição idêntica à dos vidros mesopotâmicos. É curioso que Akhenaton tenha feito tais encomendas, existindo em Amarna uma oficina de produção de vidro. Isso só poderá significar que, nessa altura, a produção de vidro no Egito seria insuficiente para satisfazer a procura.

Conhecem-se ainda testemunhos arqueológicos do comércio do vidro no Bronze Final, nomeadamente os 175 lingotes de vidro azul encontrados no barco naufragado ao largo da costa da Turquia em Uluburun, por volta de 1300

18 Acrónimo de Laser ablation inductively coupled plasma mass spectrometry.

19 Em 1887 foram encontradas casualmente em Amarna 350 tabuinhas em escrita cuneiforme, às quais foram sendo adicionadas outras, recolhidas em escavações, de tal modo que totalizam hoje 382. A maioria são cartas que foram enviadas aos faraós Amen-hotep III (1390-1352 a.C.) e Akhenaton (1352-1336 a.C.) pelos reis da Babilónia, Assíria, Hatti e Mitanni, bem como por governadores cipriotas e hititas vassalos do Egito. Daí elas serem designadas por Cartas de Amarna. Encontram-se atualmente dispersas por vários museus da Europa, Estados Unidos e Egito. 
a.C., aos quais nos referimos já na secção 2. Embora não se chegasse a esclarecer devidamente em que direção seguia o barco, a conclusão generalizada foi que ele se deslocava de leste para oeste. A princípio houve quem pensasse que tais lingotes viriam da Mesopotâmia, talvez por se admitir que foi aí que o vidro começou a ser produzido regularmente e só mais tarde no Egito. Outros consideraram que viriam do Egito, dado que na altura do naufrágio o Egito já produzia vidro e era o Estado dominante no Próximo Oriente. Posteriormente, a ideia de que a proveniência dos lingotes seria o Egito veio a ser reforçada por Nicholson e colaboradores [35] ao verificarem que alguns deles apresentam uma forma e certos sinais concêntricos na face inferior que se ajustam bem ao interior de certos cadinhos cilíndricos em cerâmica achados em Amarna.

Para pôr fim ao debate que então se estabeleceu, Jackson e Nicholson [36] procuraram determinar a proveniência dos lingotes recorrendo à análise elementar dos vidros de três deles, dois coloridos com cobalto e um outro colorido com cobre, e comparando os resultados obtidos com os alcançados por Shortland e colaboradores no seu trabalho de caracterização composicional dos vidros do Egito e da Mesopotâmia [29]. Assim, conseguiram demonstrar que os lingotes transportados no barco naufragado em Uluburun provinham, com toda a probabilidade, do Egito. É de salientar que os resultados de Jackson e Nicholson estão ainda de acordo com os de análises feitas ao vidro azul-cobalto de várias joias e peças de adorno micénicas encontradas em diversos lugares do Mundo micénico, o que prova que os Micénios importavam vidro em bruto do Egito, nomeadamente vidro azul colorido com cobalto, o qual era depois trabalhado localmente em oficinas próprias.

Provou-se, além disso, que os Micénios também importavam vidro da Mesopotâmia. Com efeito, num estudo de proveniência dos vidros de onze contas micénicas - quatro verdes (coloridas com cobre) e sete azuis (três coloridas com cobre (Figura 8) e quatro coloridas com cobalto) - levado a cabo fazendo a sua análise pelo método de LA-ICPMS, Walton e colaboradores [37] verificaram, comparando os resultados obtidos com os da caracterização composicional dos vidros egípcios e mesopotâmicos realizada por Shortland e colaboradores [29], que os vidros de cinco daquelas onze contas têm uma composição semelhante à dos vidros egípcios, e que os vidros das outras seis têm uma composição análoga à dos vidros mesopotâmicos. É de crer, portanto, que a indústria micénica de joalharia se abastecia de vidro não só do Egito como também da Mesopotâmia.

Por seu turno, Varberg e colaboradores [38] procuraram determinar a proveniência do vidro usado na manufatura de certas contas anulares azuis descobertas na Dinamarca em sepulturas da Idade do Bronze Nórdico Inicial, isto é, de 1400-1100 a.C., determinando a concentração dos elementos vestigiais nos vidros de vinte e três delas - cinco coloridas com cobalto (Figura 9) e dezoito coloridas com cobre - com auxílio dos mesmos métodos de análise que os utilizados pelos investigadores acima referidos. Verificaram deste modo que os vidros de duas das contas coloridas com cobalto têm uma composição análoga à dos vidros egípcios, e que os das três outras da mesma cor e os das dezoito coloridas com cobre têm uma composição idênti-

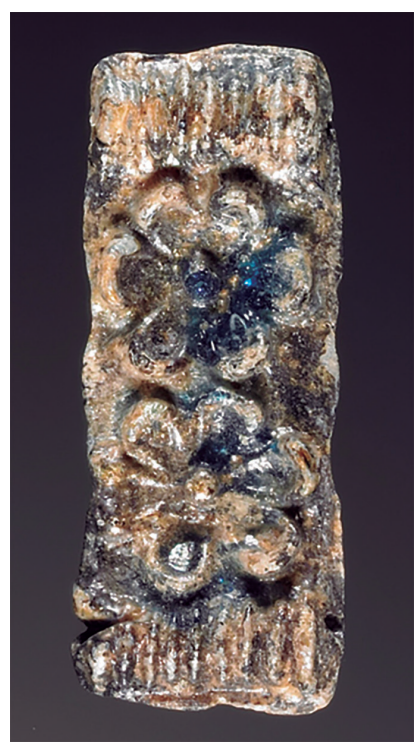

Figura 8 - Conta-pendente micénica, em vidro azul colorido com cobre, datada estilisticamente do Período Heládico Recente IIIA (1400-1300 a.C.). 2,6 x 1 x 0,5 cm. J. Paul Getty Museum, Los Angeles.

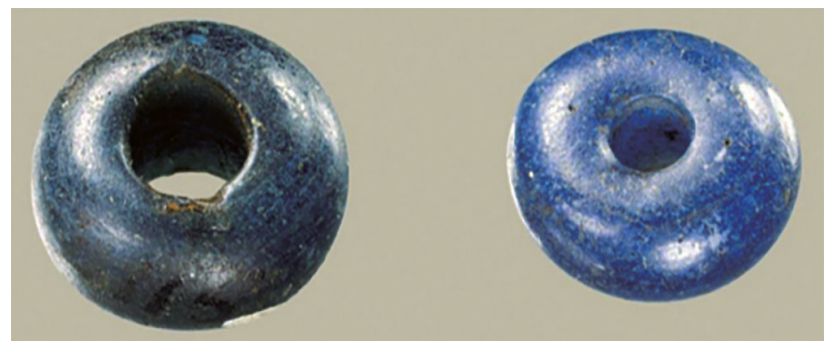

Figura 9 - Contas de vidro azul-cobalto encontradas em sepulturas do século XIV a.C. em Hesselager e Ølby, Dinamarca. Foto de A. Mikkelsen, Museu Nacional da Dinamarca [38].

ca à dos vidros mesopotâmicos. Posteriormente, Varberg e colaboradores [34] alargaram a investigação a mais contas de vidro da mesma época mas descobertas noutras regiões, designadamente na ilha dinamarquesa de Bornholm (Mar Báltico), na Caverna de Cioclovina (Roménia) e na cidade de Neustrelitz (Nordeste da Alemanha). As análises feitas a estas contas mostraram que também elas apresentam uma composição análoga à dos vidros mesopotâmicos. Concluiu-se, portanto, com base nestes resultados e em resultados semelhantes obtidos por Peche-Quilichini e colaboradores [39] na análise de contas de vidro da mesma época achadas em Campu Stefano, na Córsega, que em finais da Idade do Bronze teria existido uma rede comercial do vidro muito vasta, que se estendia desde o Egito e Próximo Oriente até à Escandinávia, por um lado, e até às costas ocidentais do Mediterrâneo, por outro.

\section{A crise civilizacional de finais da Idade do Bronze e consequências}

Convém lembrar que entre finais do século XIII a.C. e inícios do século XII a.C. ocorreram em várias regiões do Mediterrâneo Oriental e Próximo Oriente diversos acontecimentos catastróficos, quer naturais quer provocados pelo homem, que contribuíram de modo significativo para a queda das civilizações da Idade do Bronze. Atores principais de alguns desses acontecimentos foram grupos de povos de origem incerta, a que os historiadores modernos 
chamam Povos do Mar, os quais invadiram as referidas regiões, pirateando e destruindo cidades e campos à sua passagem [40].

O Egito foi atacado duas vezes: a primeira, em c. 1207 a.C., no reinado de Merneptah (1224-1204 a.C.), da qual os Povos do Mar saíram derrotados; a segunda, por volta de 1177 a.C., no reinado de Ramsés III (1184-1153 a.C.), que teve um desfecho semelhante. Relatos deste último ataque, com imagens da luta travada no delta do Nilo, foram inscritos nas paredes do templo funerário de Ramsés III em Medinet Habu (Figura 10). Todavia, embora vitorioso, o Egito nunca mais voltou a ser o Estado poderoso militar e economicamente que fora antes.

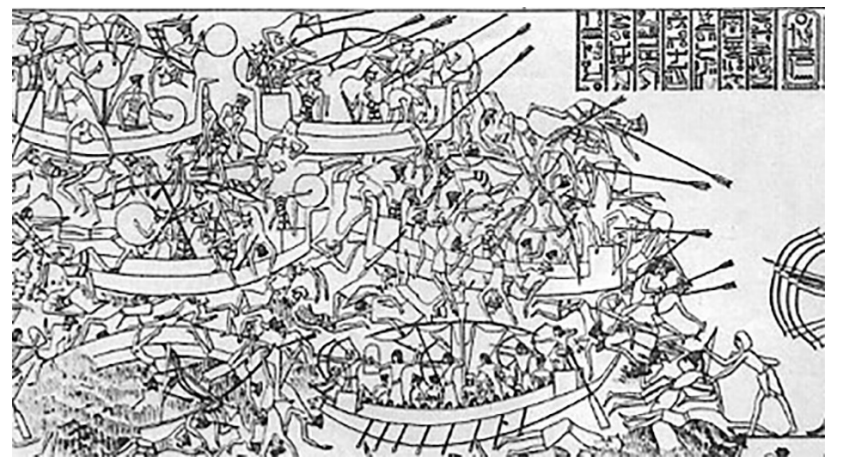

Figura 10 - Pormenor da batalha do Delta entre Egípcios e Povos do Mar, em c. 1177 a.C. Gravação na parede norte do templo funerário de Ramsés III, em Medinet Habu, Egito.

Noutras regiões mediterrânicas os ataques tiveram consequências mais graves, como se refere, a título de exemplo, a seguir. 1) Na Síria, a capital do reino de Ugarit $^{20}$ - que possuía um porto marítimo posicionado no cruzamento de rotas comerciais ligando os países da bacia do Mediterrâneo à Mesopotâmia — foi violentamente arrasada em 1190-1185 a.C., sucedendo o mesmo a outras localidades situadas mais a leste até ao rio Eufrates, e mais a sul nos territórios correspondentes aos atuais Estados de Israel e Palestina. 2) Na Anatólia, a capital do Império Hitita - Hattusa — foi arrasada em inícios do século XII a.C., tendo as escavações arqueológicas revelado a presença nos escombros de cinzas, madeiras queimadas e tijolos de adobe com escórias, sinais evidentes de que a cidade esteve sujeita a um incêndio de grandes proporções; por outro lado, a antiga cidade de Troia, que Homero perpetuou na Ilíada, foi destruída no início do século XII a.C. 3) No Chipre, diversas localidades foram palco de grandes destruições por volta de 1200 a.C. 4) Na Grécia continental, a antiga cidade de Micenas foi arrasada em c. 1250 a.C. por um tremor de terra, sendo de novo destruída entre 1190 e 1130 a.C. ao mesmo tempo que Tirinto (Figura 5) e outras cidades da mesma região.

\footnotetext{
20 Os sítios arqueológicos do porto e da cidade de Ugarit, capital do antigo Reino de Ugarit, foram descobertos por acaso no fim da década de 1920, sendo sujeitos a sucessivas escavações arqueológicas as quais se estenderam a outros sítios do mesmo Reino e prosseguiram até ao início da guerra na Síria. Dos vários artefactos encontrados é de destacar um conjunto de tabuinhas cuneiformes escritas em diferentes línguas — acádio, hitita, egípcio, hurrita, ugarito — as quais documentam quer as atividades económicas da família real e de vários mercadores, quer diversas obras da literatura, mitologia, história e religião do povo ugarito [40].
}

Na Mesopotâmia existem igualmente testemunhos de destruições antigas em várias regiões, nomeadamente na região babilónica, as quais não foram certamente feitas pelos Povos do Mar. Algumas delas talvez o tenham sido pelos Elamitas, quando o Elão invadiu aquele reino em 1158 a.C., invasão essa que levou à queda da Dinastia Cassita, reinante na Babilónia desde 1595 a.C.. Mas, tal como se verifica na maioria dos casos, não se sabe verdadeiramente quem, ou o que, as terá causado.

O certo é que, por diversas razões (tremores de terra, invasões de povos estrangeiros, rebeliões internas, variações climáticas seguidas de seca e fome, inundações, e porventura outras), as civilizações florescentes dos séculos XV-XIII a.C. — micénica, egípcia, hitita, assíria e babilónica - acabaram por se desmoronar pouco depois de 1200 a.C., desmoronamentos esses que se repercutiram nas atividades industriais e comerciais dos respetivos Estados.

A indústria do vidro não foi exceção e o mesmo terá acontecido à atividade extrativa do minério cobaltífero. Na verdade, verificou-se que o vidro encontrado nas escavações arqueológicas, em estratos respeitantes aos séculos XII-XI a.C., tem sido relativamente escasso. O seu renascimento só viria a verificar-se em finais do II milénio a.C., particularmente nos séculos IX-VIII a.C., tanto no Egito como na Mesopotâmia.

\section{Agradecimentos}

À Catarina Bettencourt Moniz, pelo traçado da Figura 5.

\section{Referências}

[1] G. Brandt, Acta literaria et scientiarum Sveciae 4 (1735) 1-10. Tradução em francês, in "Recueil des mémoires les plus intéressants de chymie et d'histoire naturelle, contenus dans les Actes de l'Académie d'Upsal, et dans les Mémoires de l'Acadèmie royale des sciences de Stockholm; publiés depuis 1720 jusqu'en 1760”, Tome I, 1764, p. 8-25.

[2] P. Enghag, "Encyclopedia of the Elements: Technical Data, History, Processing, Applications”, Wiley-VCH, Weinheim, 2004, p. 667.

[3] J.L. Marshall, V.R. Marshall, The Hexagon, vol. 94, n. ${ }^{\circ}$, Spring 2003, p. 7.

[4] J. Beckmann, “A History of Inventions, Discoveries, and Origins”, vol. I, Londres, 1846, p. 482.

[5] G. Agricola, "De Re Metallica”, traduzido a partir da primeira edição latina de 1556 por H.C. Hoover e L.H. Hoover, Dover Publications, Inc., New York, 1950, p. 214.

[6] F. Delamare, Comptes rendus des séances de l'Académie des Inscriptions et Belles-Lettres, 153e année, n. ${ }^{\circ}$ 1, 2009, pp. 305 e 308.

[7] D. Gallo, D. Sandron, Le Traité d'Antoine de Pise, facsimilé et transcription du manuscript, in C. Lautier, D. Sandron (dir.), “Antoine de Pise: L'art du vitrail vers 1400”, Paris, edições do CTHS, 2008, p. 41.

[8] H. Stege, Zeitschrift für Kunsttechnologie und Konservierung 18 (2004) 121-142.

[9] F. Delamare, ibid. 6, p. 309.

[10] J. Kunckel, “Ars vitraria experimentalis”, 1689.

[11] G. Brandt, ibid. 1, p. 38-50.

[12] P. Enghag, ibid. 2, p. 674.

[13] A.J. Shortland, C.A. Hope, M.S. Tite, Cobalt blue painted pottery from $18^{\text {th }}$ Dynasty Egypt, in M. Maggetti, B. Messi- 
ga (eds.), “Geomaterials in Cultural Heritage”, Geological Society, London, Special Publications, 2006, 257, 91-99.

[14] J. Riederer, Archaeometry 16 (1974) 102-109.

[15] W. Noll, Mineralogy and technology of the painted ceramics of ancient Egypt, in M.J. Hughes (ed.), "Scientific Studies in Ancient Ceramics”, British Museum Occasional Papers, 19, 1981, 143-54.

[16] Th. Rehren, I.C. Freestone, J. Archaeological Sci. 56 (2015) 233-241.

[17] P.T. Nicholson, UCLA Encyclopedia of Egyptology, 2009, http://digital2.library.ucla.edu/viewItem.do?ark=21198/ zz0017jtts.

[18] Th. Rehren, E.B. Pusch, Science 308 (2005) 1756-1758.

[19] M. Smirniou, Th. Rehren, Archaeometry 53 (2011) 58-80.

[20] M. Smirniou, Th. Rehren, G. Gratuze, Archaeometry 60 (2018) 502-516.

[21] Th. Rehren, E.B. Pusch, Crushed rock and molten salt? Some aspects of the primary glass production at Qantir/PiRamesse, in C. Jackson, E. Wager (eds.), "Vitreous Materials in the Late Bronze Age Aegean: A Window to the East Mediterranean World”. Oxbow Books, Oxford, 2008, 14-33.

[22] E.B. Pusch, Th. Rehren, Hochtemperatur-Technologie in der Ramses-Stadt: Rubinglas für den Pharao, Band 6, Teil 1 Text, Hildesheim, 2007, 146-157.

[23] M.S. Tite, A. Shortland, Y. Maniatis, D. Kavoussanaki, S.A. Harris, J. Archaeological Sci. 33 (2006) 1284-1292.

[24] W.M.F. Petrie, “Tell el-Amarna”, Methuen, London, 1894.

[25] C.M. Jackson, P.T. Nicholson, Compositional analysis of the vitreous materials found at Amarna, in P.T. Nicholson (ed.), "Brilliant things for Akhenaten: the production of glass, vitreous materials, and pottery at Amarna site O45.1”, Egypt Exploration Society, London, 2007, 101-116.

[26] C. Pulak, The Uluburun shipwreck and Late Bronze Age trade, in: J.Aruz, K. Benzel, J.M. Evans (eds.), "Beyond
Babylon: Art, Trade, and Diplomacy in the Second Millennium BC”, The Metropolitan Museum of Art, New York, 2008, 289-310.

[27] J.D. Muhly, Expedition Magazine 53.1 (2011) 39.

[28] Th. Rehren, Archaeology International 9 (2005) 40-42.

[29] A. Kaczmarczyk, The source of cobalt in ancient Egyptian pigments, in J.S. Olin, M.J. Blackman (eds.), "Proceedings of the $24^{\text {th }}$ International Archaeometry Symposium”, Smithsonian Institution Press, Washinton, D.C., 1986, 369-376.

[30] A.J. Shortland, M.S. Tite, I. Ewart, Archaeometry 48 (2006) 153-168.

[31] M. Walton, K. Eremin, A. Shortland, P. Degryse, S. Kirk, Archaeometry 54 (2012) 835-852.

[32] A. Shortland, N. Rogers, K. Eremin, J. Archaeological Sci. 34 (2007) 781-789.

[33] W.L. Moran, “The Amarna Letters”, Baltimore, John Hopkins University Press, 1992.

[34] J. Varberg, B. Gratuze, F. Kaul, A.H. Hansen, M. Rotea, M. Wittenberger, J. Archaeological Sci. 74 (2016) 184-194.

[35] P.T. Nicholson, C.M. Jackson, K.M. Trott, J. Egyptian Archaeology 83 (1997) 143-153.

[36] C.M. Jackson, P.T. Nicholson, J. Archaeological Sci. 37 (2010) 295-301.

[37] M.S. Walton, A. Shortland, S. Kirk, P. Degryse, J. Archaeological Sci. 36 (2009) 1496-1503.

[38] J. Varberg, B. Gratuze, F. Kaul, J. Archaeological Sci. 54 (2015) 168-181.

[39] K. Peche-Quilichini, J. Cesari, F. Leandri, L. BellotGurlet, E. Canobbio, B. Gratuze, C. Leandri, C. Paris, ArchéoSciences 40 (2016) 65-81.

[40] E.H. Cline, “1177 B.C.: The Year Civilization Collapsed”, Princeton University Press, 2014.

Antropocénico e plásticos

Maria Elvira Callapez e Teresa Salomé Mota

Química - Boletim da Sociedade Portuguesa de Química 2019, 43 (152), 56-59.

Por lapso, neste artigo não foi incluído o seguinte texto:

As autoras agradecem à Fundação para a Ciência e a Tecnologia o financiamento do projeto "O Triunfo da Baquelite Contributos para uma História dos Plásticos em Portugal” (Ref. a PTDC/IVC-HFC/5174/2014). 